\title{
Pressure Distribution On A Flat Plate In The Context of The Phenomenon of The Coanda Effect Hysteresis
}

Aldona Skotnicka-Siepsiak ( $\sim$ aldona.skotnicka-siepsiak@uwm.edu.pl ) University of Warmia and Mazury in Olsztyn

\section{Research Article}

Keywords: Coanda effect, Coanda effect hysteresis, pressure distribution on a plate.

Posted Date: November 17th, 2021

DOI: https://doi.org/10.21203/rs.3.rs-1054725/v1

License: (c) (i) This work is licensed under a Creative Commons Attribution 4.0 International License.

Read Full License 


\section{Abstract}

As a result of the Coanda effect, a symmetrical free jet will flow as an asymmetrical wall jet. At the same time, at the obstacle along which the flow is observed, the wall jet generates pressure distribution. In this study, the obstacle located at the diffuser outlet is a flat plate with a variable inclination angle. The article presents results of the study on pressure distributions on a flat plate with a variable angle of inclination. What is new, however, is that the presented results of the experimental research include the influence of the Coanda effect hysteresis on the pressure distribution on the plate. The article shows how pressure distributions change on the plate depending on whether the initial angle of inclination was 0 degree and was increased gradually in the course of the experiment until a detachment of the jet flowing from the plate was observed, or the initial angle of inclination was close to 90 degrees in the primal state and as the angle of the plate inclination was decreased, the jet flowing towards the plate reached the state of attachment to the plate surface.

\section{Introduction}

In civil engineering, much attention is paid to the issue of a free jet. In general theoretical terms, a free jet is symmetrical. The symmetry axis is an extension along the jet of the diffuser symmetry axis. Four main zones can be distinguished in the course of the jet [1]. A short core zone, in which the axial velocity does not change, has a length of approx. four characteristic dimensions of the diffuser. Within this zone, the core of the jet can be distinguished, in which, in the axis of the jet, the initial velocity is maintained. The second one, a transition zone, is that in which the distribution of velocities in the cross-section, characteristic of free jets, arises. The length of the zone is determined by the diffuser design. The third zone is that of a fully established turbulent flow, in which there is a proportional drop in axial velocity in relation to the distance from the outlet. The zone of diffuser jet degradation is a zone of the dominant impact of the forces of internal friction, often referred to as a "die away zone", in which the axial velocity decreases rapidly, and the jet ceases to move in an orderly manner in a particular direction [2].

A free jet is used in multiple technical solutions. In the Google Patents database alone, there are more than 135,000 records containing the phrase "free jet" [3]. Engineering applications of a water jet are among the more popular solutions [4], [5], [6]. Another field in which the issue of a free jet is of particular importance is ventilation and air conditioning in the analysis of an air jet flow [7], [8], [9] or [10], [11].

There are numerous research papers dedicated to the issue of a free jet. Older studies include, for example, papers by Corrsin [12], Schwarc [13], Wygnanski and Fiedler [14] or Rajaratnam [15]. However, this issue continues to be an area of research interest. Studies that can be mentioned here include, for example, those by Lipari and Stansby [16], who analysed the issue of incompressible turbulent round jets issuing into a large, ideally infinite, quiescent domain. On the other hand, de la Torre et al. [17] addressed the process of a circular free-falling jet entering an idle pool. Abdel-Rahman [18] considered the initial and boundary conditions affecting the jet. A large number of studies use numerics for research purposes [19], 
[20] or [21]. The issue of turbulent jet control using artificial intelligence is addressed in an article by Zhou et al. [22].

For the formation and characteristics of a free jet, the diffuser is of key importance [23], [24], [25], [26], [27]. Studies by Hussein et al. [28] or [29], or by Mi et al. [30] are among the papers dedicated to the geometry of a jet generated by a round diffuser. On the other hand, examples of analyses dedicated to a rectangular nozzle include [31] or [32]. More atypical solutions in this regard have also been presented, e.g. for an elliptical nozzle [33], [34] or a lobed nozzle [35], [36]. The diffuser shape also affects the number of symmetry axes that can be distinguished in a jet.

However, the symmetrical nature of a free jet can be very easily disturbed. For this purpose, it is sufficient to place an appropriate obstacle close enough to the jet flowing out of the diffuser, which will result in a generated wall jet. Sawyer [37] presented two cases: where a flat plate with a variable inclination angle is attached to one of the diffuser edges at the point of jet outflow, and the outflow of a two-dimensional jet from a diffuser that is located at a distance $h$ from the perpendicular plate. The study focused on the development of mathematical models describing the distribution of velocities and pressure and the geometry of the flow. On the other hand, Newman, in his article, [38] considers two following cases: the flow of a two-dimensional, incompressible turbulent jet around a circular cylinder and the deflection of a two-dimensional, incompressible jet under the action of a deflected flat plate. A study by Levin and Manion [39] modified the distance of the plate location in relation to the diffuser and the inclination angle of the flat plate. The displacement of the plate in relation to the diffuser was a multiple of the gap width and amounted to $0,2,4$, or 10 , respectively. The inclination angle of the plate ranged from $0^{\circ}$ to $55^{\circ}$. A study by Lai and Lu [40] examined the distribution of velocities and turbulence, and the location of the position of the point of jet reattachment to the plate, at different positions of its inclination. Tests were conducted for a wall jet (the plate inclination angle of $a=0^{\circ}$ ), jets at the plate inclination at an angle of $a$ $=15^{\circ}, a=30^{\circ}$ and $a=45^{\circ}$, and a free jet (the plate inclination angle of $a=90^{\circ}$ ), at a quantity of $R e=10,000$. The testing was conducted using a TSI IFA 100 constant-temperature anemometer. In order to determine the position of jet reattachment to the plate, measurements of pressure distribution on the plate were carried out and a visualization using threads attached to the plate was performed. Moreover, visualizations using oil film and fumigation techniques were performed. The obtained results indicated that with an increase in the plate inclination angle value, there was both a more rapid decline of the axial velocity and more rapid propagation of the jet. Consequently, due to the increase in the plate inclination angle, both the shortening of the jet core zone and an increase in the jet volume area in which entrainment occurs are observed. An extension of the research into the distribution of velocities and the turbulence of a jet adjacent to the deflectable plate to include the consideration of the distance of the deflectable plate from the diffuser can be found in an article by Nasr and Lai [41]. In the cited article, the coefficient of the plate distance from the diffuser amounted to $b / D=2.125$. The testing was conducted for the plate inclination angle of $a=0^{\circ}$ (wall jet), $a=15^{\circ}$ and $a=30^{\circ}$. At the nozzle outlet, a quantity of $\operatorname{Re}=6,100$. The study used a two-component Doppler laser anemometer. 
This phenomenon of deflection of the initial jet axis due to the proximity of the baffle is referred to as the Coanda effect [42]. The first written notices on observing the Coanda effect were made by Young in 1800 [43]. The phenomenon was also observed by Osborne Reynolds who, in 1870, analysed behaviours of a ball placed on the top of a vertical stream of water [44]. The Coanda effect is named after the name of the engineer Henri Marie Coanda, and was observed during his studies on the "Coanda 1910" plane, that was the first machine to use an early model of a jet engine. Presently, the phenomenon has been applied to numerous technical solutions which include respirators, dryers, blood filters and blood collecting devices, sports cars, hovercrafts, electric toothbrushes, vacuum-cleaners, cyclonic separators for air cleaning, machines for electronic chip cooling, industrial, agricultural, and automated pumps [45].

Some results of the research into pressure distributions on a plate may also be found in numerous studies on the Coanda effect. The studies by Newman [38], Sawyer [46], or Lai and Lu [40] may be provided here as examples. Those works, however, always dealt with the Coanda phenomenon and did not view the issue of pressure distribution in the aspect of hysteresis.

The phenomenon of the Coanda effect hysteresis was described for the first time by Newman [38]. It was characterized as a dependence of the state of the air jet flow (the free jet or the one attached to a flat plate is observed) on the angle of a plate inclination. In a defined range of angular a values for the inclination of a flat plate, which depend on a relation between the I length of the plate and the $b$ width of a nozzle, there are two cases of air flow possible: the flow in a form of a free jet or the flow of a jet attached to the plate with an observable separation bubble.

There are few articles on the hysteresis of the Coanda effect. In the article by Allery et. al. [47], the authors described two types of own studies on occurrences of the Coanda effect hysteresis:

- the $a$ value for the angle of plate inclination was changed and values of the Reynolds number for jet detachment $\left(\mathrm{Re}_{\mathrm{D}}\right)$ and reattachment $\left(\mathrm{Re}_{\mathrm{A}}\right)$; were identified

- the velocity was changed and critical values for angles of jet detachment $\left(a_{D}\right)$ and reattachment $\left(a_{A}\right)$ were identified.

The range of occurrences for the Coanda effect hysteresis reported in other sources was confirmed by experimental research, the large eddy simulation (LES), and the proper orthogonal decomposition (POD). The cited results indicate that it is enough to define values of the $\operatorname{Re}_{A}$ and $a_{A}$ parameters to identify the parameters of jet attachment or reattachment for a given geometry of the system (the plate length and the nozzle width). However, to identify the parameters of jet detachment, the parameters $\operatorname{Re}_{D}$ and $a_{D}$ should be defined. An analysis of the critical value of the Reynolds number in the direction of detachment makes it possible to notice, that the value increases to a small degree for the values of the plate inclination: $21^{\circ} \leq a \leq 38^{\circ}$. On exceeding the value of $a>38^{\circ}$, it increases significantly. A similar dependence also refers to the critical value of the Reynolds number examined in the direction of the jet reattachment. There appears a significant increase of the $\mathrm{Re}_{\mathrm{A}}$ value for the values of plate inclination ranging $33^{\circ} \leq a \leq 38^{\circ}$. 
A closer look at the range of the hysteresis occurrence area makes it possible to notice that as angular a values for plate inclination increase, there also occurs an increase of the value: $\triangle R e=R_{A}-R_{D}$. For the angle of plate inclination of $a=21^{\circ}$ it is, respectively, $\Delta R e=150$ while for the value of $a=39^{\circ}$ it is $\Delta R e=$ 9000. When preserving a constant velocity, as the Reynolds number increases, there also occurs an increase of the value: $\Delta a=a_{A}-a_{D}$.

The study aimed to analyze the pressure distribution on a flat plate with a variable inclination angle, which is located at a flat diffuser outlet, considering the Coanda effect histeresis..

\section{Methods}

Own experimental studies on identifying the occurrence area of the Coanda effect hysteresis and the pressure distribution on a flat plate with a variable angle of inclination were conducted at the measuring station of the Faculty of Geoengineering at the University of Warmia and Mazury in Olsztyn. The area of the measuring station was $3.850 \times 2.009 \mathrm{~m}$ and its height was $2.290 \mathrm{~m}$. The air was delivered to the experimental system by a sucking duct with the diameter of $0.25 \mathrm{~m}$ and length of $5.30 \mathrm{~m}$. An air intake with regulated flow and diameter of $0.40 \mathrm{~m}$ was mounted at the duct inlet. An orifice plate for static pressure measurements was placed in the sucking duct. The duct was connected by elastic joints to a WPO-type fan that was equipped with a three-phase fixed-gear induction motor with an EFF2-class squirrel-cage. The motor was connected to the fan by a fan belt and it was launched manually. On the pressing side of the fan, a diffuser in the shape of the Witoszyński nozzle was mounted. The height of the diffuser $(h=0.60 \mathrm{~m})$ and its width $(b=0.20 \mathrm{~m})$ were constant. At the nozzle outlet, a plate with a variable angle of inclination was mounted and it formed an extension of one of the diffuser edges (Figure 7). The plate length was I $=1.00 \mathrm{~m}$. The angle of the plate inclination was set manually and reading its value was possible by a scale on a rod that formed a slide for the inclined plate.

On the plate with a variable angle of inclination, there were 48 orifices, situated $20 \mathrm{~mm}$ away from each other, which were connected to a liquid manometer by elastic ducts. In the diffuser, there were two orifices that were also connected to the liquid manometer by elastic ducts. The liquid manometer was equipped with 51 glass tubes that were filled with a manometric liquid (alcohol) with the density of $\rho=816 \mathrm{~kg} / \mathrm{m}^{3}$. The plate of the liquid manometer was inclined to the angle of $\beta=30^{\circ}$ to obtain a higher accuracy of readings. The readings of the column of the manometric liquid were performed manually. An indication of the zero value was equivalent to a lack of the air flow in the research station. The accuracy of the readings was $1 \mathrm{~mm}$, which corresponds to the value of $4.001 \mathrm{~Pa}$.

Studies of pressure distribution on a plate were performed for ten measuring sessions with the Reynolds number ranging $16,192 \div 42,240$. Identifying the $p_{i}$ value for pressure in 48 measuring points on a plate with the length of $I=1.00 \mathrm{~m}$ was conducted using the formula:

$$
p_{i}=\rho g h_{i} \sin (\beta)
$$


on the basis of the known value of the manometric liquid density ( $\rho)$, the gravitational acceleration (g), and the experimentally determined column of the liquid in particular tubes of the liquid manometer $\left(\mathrm{h}_{\mathrm{i}}\right)$.

During the studies in the direction of detachment, the plate was initially inclined to the angle $a=0^{\circ}$. The angle was increased gradually every $5^{\circ}$ until the $a_{D}$ value of the critical detachment angle was reached. The studies in the direction of the jet reattachment to the plate were started with placing the plate in the maximum angle of inclination (about $90^{\circ}$ ) when a free air flow was observed. The angle of inclination was decreased until the jet reattachment was noticed. Then, the plate inclination was discretely decreased (by multiples of $5^{\circ}$ ) until reaching the $0^{\circ}$ value. A measurement of the pressure distribution on the plate was performed for every of the consecutive plate inclinations.

\section{Results And Discussion}

The obtained results for the values of the critical angles of jet detachment $\left(a_{D}\right)$ and jet reattachment $\left(a_{A}\right)$ (Figure 1) confirm the span of the area of the Coanda effect hysteresis known from the literature $[48,49]$. The value differences between the critical $a_{D}$ detachment and $a_{A}$ attachment angles are about $15^{\circ}$. As the Reynolds number increases, values of the critical $a_{D}$ detachment and $a_{D}$ attachment angles decrease.

When examining in the direction of detachment, zero values for the pressure in almost every measuring session were recorded for the lowest values of the plate inclination of $a=0^{\circ} \div 15^{\circ}$. The only exception was the session characterized by the lowest value of the Reynolds number $(\operatorname{Re}=16,192)$ for which in the initial area of the plate, directly behind the nozzle, there was an area of negative pressure of about $p_{i}=$ $\bigotimes 12 \mathrm{~Pa}$ on a section of the approximate length of $0.20 \mathrm{~m}$. Increasing the plate inclination to the angle of a $=20^{\circ}$ resulted in appearing of a small area of about $0.02 \mathrm{~m}$ of slight negative pressure $\left(\mathrm{p}_{\mathrm{i}}=\nabla 8 \mathrm{~Pa}\right)$ for the $\operatorname{Re}=42,240$ measuring session and of about $0.22 \mathrm{~m}$ for the $\operatorname{Re}=16,192$ measuring session. When inclining the plate to the angle of $a=25^{\circ}$, some clearer fluctuations appeared in the pressure values in the initial area of the plate. For the measuring session with the highest value of the Reynolds number, the

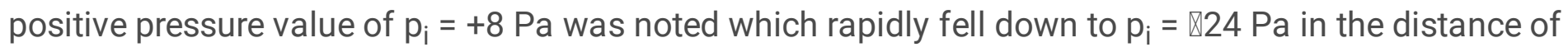
$0.04 \mathrm{~m}$ away from the nozzle and then increased and got normalized on the level of $p_{i}=0 \mathrm{~Pa}$ in the distance of $0.08 \mathrm{~m}$. As for the remaining measuring sessions, in the area of small negative pressure values, the value directly behind the nozzle fell down and stabilized on the level of $p_{i}=0 \mathrm{~Pa}$ in the distance of $0.08 \mathrm{~m}$ away from the nozzle. For the measuring session characterized by the lowest initial value of $\operatorname{Re}=16,192$, the constant pressure value remained on the level of $p_{i}=\nabla 12 \mathrm{~Pa}$ within the section of about $0.20 \mathrm{~m}$ and then increased rapidly and stabilized on the level of $\mathrm{p}_{\mathrm{i}}=0 \mathrm{~Pa}$. Increasing the angle of the plate inclination to the value of $a=30^{\circ}$ resulted in extending the area where the pressure fluctuated from the zero value. For all the measuring sessions, positive pressure values were noted directly behind the nozzle and then they decreased rapidly reaching maximum negative values characteristic for a given inclination in the distance of about $0.05 \mathrm{~m}$ from the nozzle. In the further part of the flow, a gradual increase of the pressure value was observed and it got normalized on the level of $p_{i}=0 \mathrm{~Pa}$ in the distance of about $0.15 \mathrm{~m}$. In the case of inclining the plate to the angle of $a=35^{\circ}$, the area at the beginning of the 
plate, which is characterized by positive pressure values, was extended to about $0.08 \mathrm{~m}$. For the measuring session with the highest value of the Reynolds number, the maximum pressure value was noted in the distance of $0.04 \mathrm{~m}$ from the nozzle. For the remaining measuring sessions, the maximum pressure values were noted directly behind the nozzle. In the further part of the flow, a rapid decrease in the pressure was visible and it reached critical values in the distance of about $0.12 \mathrm{~m}$ from the nozzle. Further on, an increase of the pressure was noticed on the plate until it reached the value of $0 \mathrm{~Pa}$ in the distance of about $0.24 \mathrm{~m}$ from the nozzle. For the measuring series with $\operatorname{Re}<41,855$, when the plate was inclined to the angle of $a=40^{\circ}$, maximum positive pressure values were recorded - those were the maxima for all the sessions at various plate inclinations. An extension of the area of high pressure at the initial part of the plate was visible, where a slight increase of the pressure to the maximum $p_{i}$ values was observed. They were reached in the distance of about $0.08 \div 0.12 \mathrm{~m}$ behind the nozzle. Then, a rapid decrease in the pressure values was observed, until it reached the maximum recorded negative values at the given inclination angle in the distance of about $0.18 \div 0.20 \mathrm{~m}$ away from the nozzle. In the further part of the flow, the pressure increased to a constant value close to $0 \mathrm{~Pa}$ that was reached in the distance of about $0.36 \mathrm{~m}$. In the case of five measuring sessions, a normalized, constant pressure value in the further area of the plate reached $p_{i}=\varangle 4 \div \varangle 8 \mathrm{~Pa}$. Further increasing of the angle of the plate inclination to the values of $a=45^{\circ}$ and $a=50^{\circ}$ resulted in an extending the area where varied pressures occurred and in moving localizations of the points characterized by the highest and the lowest recorded pressure values away from the nozzle, as well as moving away the beginning of the area where the pressure got stabilized on the plate.

As for the plate inclination to the angle of $a=50^{\circ}$, the value of the pressure stabilized on the level of about $\mathrm{p}_{\mathrm{i}}=\varangle 20 \mathrm{~Pa}$ in the distance of about $0.70 \mathrm{~m}$ away from the nozzle. When the plate inclination was a $=45^{\circ}$, the pressure got stabilized on a stable level of $0 \div \otimes 8 \mathrm{~Pa}$ somewhere in the middle of the plate length (about $0.50 \mathrm{~m}$ ). A decrease in maximum and minimum pressure values as the angle of the plate inclination increased was visible at the same time. As for the plate inclination to the critical detachment angle, the value of which was dependent on the Re values for particular sessions, stable pressure values were visible in the initial area of the plate (within the section of about $0.08 \mathrm{~m}$ ). For the measuring session with the lowest values of $\operatorname{Re}=16,192$, some negative pressure values were observed. For the $\operatorname{Re}=24,284$ and $R e=29,737$ measuring sessions, the initial value of the pressure was $0 \mathrm{~Pa}$. In the further distances from the nozzle, a gradual increase of the pressure took place until the length of $0.40 \mathrm{~m}$ was reached. As the distance from the nozzle was increased, a decrease in the pressure was noticeable until it reached maximum negative pressure values in the distance of about $0.70 \mathrm{~m}$. Some stable, negative pressure values, on the level of about $p_{i}=\varangle 35 \mathrm{~Pa}$ remained then until the final sections of the plate. Within the final $0.04 \mathrm{~m}$ of the plate, there was a slight increase of the pressure to the value of about $\mathrm{p}_{\mathrm{i}}=\llbracket 20 \mathrm{~Pa}$. A sample graph for the pressure distribution on the plate with the variable angle of inclination when examined in the direction of detachment has been presented in Figure 2 .

Initially, when examining in the direction of attachment, a flow of free jet was observed at large angles of the plate inclination (about $90^{\circ}$ ), which resulted in the zero values for the column of the manometric 
liquid and the pressure. First readings of the manometric liquid column height value different to 0 were taken for the critical value of the jet attachment angle. In that study case, an increase of the pressure was visible and it reached its maximum value in the distance of about $0.10 \mathrm{~m}$ away from the nozzle. Then, a rapid decrease of the pressure occurred, until it reached the maximum recorded negative values in the distance of about $0.14 \div 0.20 \mathrm{~m}$ away from the nozzle. Then, the pressure got stabilized on the level of about $p_{i}=0 \mathrm{~Pa}$. Only for the measuring session with the lowest value of $\operatorname{Re}=16,192$, the stabilized pressure remained on the level of $p_{i}=\llbracket 8 \mathrm{~Pa}$. At the plate inclination of $35^{\circ}$, which was the critical $a_{A}$ value of the jet reattachment angle for two measuring sessions, a reduction of the area of the pressure fluctuations was visible. The pressure stabilized on the level of about $p_{i}=0 \div \nabla 4 \mathrm{~Pa}$ in the distance of about $0.20 \div 0.36 \mathrm{~m}$ away from the nozzle. For the majority of the measuring sessions, a decrease in the pressure values occurred directly behind the nozzle, until it reached the minimum pressure value in the distance of about $0.12 \mathrm{~m}$ away from the nozzle. Then, a gradual increase of the pressure was observed, until it got stabilized on the level of about $0 \mathrm{~Pa}$. As the angle of the plate inclination was decreased more, a further reduction of the area of pressure fluctuations was visible, as well as stabilization of the pressure values on the normalized level of about $0 \mathrm{~Pa}$. At first, the recorded positive value of the pressure fell down rapidly to the maximum observed negative value. Then, it increased gradually and stabilized on the level of about $0 \mathrm{~Pa}$ in the distance of about $0.20 \mathrm{~m}$ away from the nozzle. Further decreasing the angle of the plate inclination by consecutive $5^{\circ}$ until the value of $a=25^{\circ}$ showed some positive pressure values in the initial area of the plate for the measuring series with the highest values of the Reynolds number $(\mathrm{Re}=$ $42,240 \div 40,075$ ). The pressure fell down reaching the maximum negative values in the distance of about $0.04 \mathrm{~m}$ away from the nozzle and then increased and stabilised on the level of $0 \mathrm{~Pa}$ in the distance of about $0.12 \mathrm{~m}$. As for the remaining measuring sessions, the zero values were recorded along the whole length of the plate. For the angles of the plate inclination ranging $a=0^{\circ} \div 20^{\circ}$, the zero pressure values were observed along the whole plate. A sample graph for the pressure distribution on the plate with the variable angle of inclination when examined in the direction of attachment has been presented in Figure 3.

A comparison of pressure distributions on a plate for the values of critical detachment and attachment angles (Figure 4) shows that when examining in the direction of detachment, a much longer area of pressure fluctuations on the plate was noticed and, practically, it includes its total length. When studying the critical attachment angles, the pressure was stabilized on the level of about $p_{i}=0 \mathrm{~Pa}$ already in the distance of about $0.40 \mathrm{~m}$ away from the nozzle. Also, when examining in the direction of attachment, much higher positive and negative values were recorded for the critical angles than in the case on the same values of the Re number when placing the plate to the critical detachment angles.

When analysing the results of the examinations in the direction of the jet reattachment, it is interesting that the maximum pressure values recorded in that study were noticed for the same values of the angle of the plate inclination for which maximum pressure values were recorded in the examinations in the direction of detachment. The minimum pressure values in the examination in the direction of reattachment were noticed when the plate was inclined to the critical $a_{A}$ reattachment angle and they 
came very close to the minimum values recorded in the examinations in the direction of detachment both in respect of the angle of the plate inclination and the pressure values.

It can be noticed that for the discussed minimum and maximum pressure values that were recorded in the examinations in the direction of detachment or in the direction of attachment, not only the values for the angle of the plate inclination that they were recorded at in particular sessions are in accordance. Their values within particular measuring sessions are also convergent. For a study with a defined value of the Reynolds number, the maximum and minimum pressure values recorded in the examinations in the direction of on detachment are in accordance with the values recorded in the examinations in the direction of the jet reattachment (Figure 5). The analysis of the maximum and minimum recorded $p_{i}$ pressure values makes it possible to notice that an increase of the Reynolds numbers results in an increase of the deviation from zero for the minimum and maximum pressure values recorded in the examinations in the direction of detachment or in the direction of attachment. As for the study characterized by the highest Reynolds number $(\operatorname{Re}=42,240)$, the difference between the maximum and minimum pressure value recorded for the whole study was about $300 \mathrm{~Pa}$. In the case of the study with $\mathrm{Re}$ $=16,192$, that difference was only about $52 \mathrm{~Pa}$.

The noticed convergence of angular range of occurrences and the maximum and minimum values of pressure for the examinations in the direction of detachment and attachment makes it interesting to compare the pressure distribution on the plate in both studies at the same value of the plate inclination (Figure 6).

It may be noticed that, regardles of examining in the direction of detachment or attachment, if the Coanda effect was noticed on the plate, the same course of the curve for the pressure distribution on the plate was observed for the same values of the angle of the plate inclination.

\section{Conclusion}

Hysteresis has got a very strong influence on the range of occurrences of the Coanda effect on a flat plate. An air jet can flow as a one that is attached to the surface of a flat plate (which results in fluctuations of the pressure values the on a plat plate) or as a free one (which is of no influence on the distribution of the zero pressure values the on a plate). Depending on the initial value and direction of the change in the angle of plate inclination, three areas of angular values may be distinguished, which determine both the behaviour of an air jet in the context of the Coanda effect hysteresis, as well as the pressure distribution on a flat plate:

- an area where an attachment of the jet to the plate surface is always visible - it is the area with the lowest angular a values for the plate inclination, lower than the values of the critical reattachment angle $\mathrm{a}<\mathrm{a}_{\mathrm{A}}$;

- an area where a free air flow, with no interaction with the flat plate, is always visible - the area occurs for the highest ranges of the a angle of the plate inclination, for angles higher than the value of the 
critical detachment angle $a>a_{D}$;

- an area where both, a free air flow and an attachment to the plate surface, may be observed - the range of that area is about $15^{\circ}$. As the values of the Reynolds number decrease, the critical values for the $a_{D}$ detachment angle and the $a_{A}$ attachment angle increase for the flow.

The pressure distributions observed on the surface of a flat plate in the first area, where the angle of plate inclination is $a<a_{A}$, are independent from the hysteresis of the Coanda effect. The initial value for the $a$ angle of plate inclination nor the direction of the change of the a angle have no influence on the obtained results of pressure distribution. Regardless of examining in the direction of detachment or attachment, analogical results for the pressure distribution are obtained for the same values of the angle of plate inclination.

The phenomenon of the Coanda effect hysteresis is of key importance for the pressure distribution on a flat plate in the last of the aforementioned areas $\left(a_{A}<a<a_{D}\right)$. When examining in the direction of the air jet reattachment, the jet in that area flows regardless of the plate, on which the zero values are recorded for the pressure. However, when examining in the direction of detachment, as the a angle of plate inclination increases, a gradual decrease in the pressure on the plate surface is visible and the area of varied pressure becomes longer until a critical value for the $a_{D}$ detachment angle is reached.

Occurrences of the Coanda effect hysteresis also result in obtaining different pressure distributions on a plate surface inclined to the critical $a_{D}$ detachment and $a_{A}$ attachment angles.

\section{Declaration}

Data availability

All data generated or analysed during this study are included in this published article.

\section{References}

1. Zhivov, A., Skistad, H., Mundt, E., Posokhin, V., Ratcliff, M., Shilkrot, E., \& Strongin, A. (2001). Principles of air and contaminant movement inside and around buildings. In Industrial ventilation design guidebook (pp. 415-599). Academic Press.

2. 2009 ASHRAE Handbook - Fundamentals (SI Edition). (2009) American Society of Heating, Refrigerating and Air-Conditioning Engineers, Inc. (ASHRAE). Retrieved from https://app.knovel.com/hotlink/toc/id:kpASHRAE37/ashrae-handbook-fundamentals/ashraehandbook-fundamentals; (access 07.20.2021).

3. https://patents.google.com/?q=free+jet\&oq=free+jet; (access 07.20.2021).

4. Momber, A. W. (Ed.). (1998). Water jet applications in construction engineering. Rotterdam, Netherlands: AA Balkema. 
5. Kulekci, M. K. (2002). Processes and apparatus developments in industrial waterjet applications. International Journal of Machine Tools and Manufacture, 42(12), 1297-1306.

6. Li, G. S., \& Shen, Z. H. (2005). Advances in researches and applications of water jet theory in petroleum engineering [J]. Petroleum Exploration and development, 1.

7. Magnier-Bergeron, L., Derome, D., \& Zmeureanu, R. (2017). Three-dimensional model of air speed in the secondary zone of displacement ventilation jet. Building and Environment, 114, 483-494.

8. Zhang, J., Wang, J., Gao, J., Cao, C., Lv, L., Xie, M., \& Zeng, L. (2020). Critical velocity of active air jet required to enhance free opening rectangular exhaust hood. Energy and Buildings, 225, 110316.

9. Miltner, M., Jordan, C., \& Harasek, M. (2015). CFD simulation of straight and slightly swirling turbulent free jets using different RANS-turbulence models. Applied thermal engineering, 89, 11171126.

10. Essel, E. E., Tachie, M. F., Agelin-Chaab, M., Koupriyanov, M., \& Tully, B. (2013). Particle image velocimetry measurements in curved turbulent jets produced from a slot diffuser. Experimental thermal and fluid science, 49, 169-184.

11. Kalmár, F., \& Kalmár, T. (2018). Study of human response in conditions of surface heating, asymmetric radiation and variable air jet direction. Energy and Buildings, 179, 133-143.

12. Corrsin, S. (1943). Investigation of flow in an axially symmetrical heated jet of air. California Inst Of Tech Pasadena.

13. Schwarz, W. H. (1963). The radial free jet. Chemical Engineering Science, 18(12), 779-786.

14. Wygnanski, I., \& Fiedler, H. (1969). Some measurements in the self-preserving jet. Journal of Fluid Mechanics, 38(3), 577-612.

15. Rajaratnam, N. (1976). Turbulent jets. Elsevier.

16. Lipari, G., \& Stansby, P. K. (2011). Review of experimental data on incompressible turbulent round jets. Flow, turbulence and combustion, 87(1), 79-114.

17. de la Torre, R. R., Kuchta, M., \& Jensen, A. (2020). Experiments on air entrainment produced by a circular free falling jet. International Journal of Multiphase Flow, 132, 103424.

18. Abdel-Rahman, A. (2010). A review of effects of initial and boundary conditions on turbulent jets. WSEAS transactions on Fluid Mechanics, 4(5), 257-275.

19. Samarbakhsh, S., \& Kornev, N. (2019). Simulation of a free circular jet using the vortex particle intensified LES (VாLES). International Journal of Heat and Fluid Flow, 80, 108489.

20. Petracci, I., Angelino, M., Di Venuta, I., Boghi, A., \& Gori, F. (2019). Experiments and numerical simulations of mass transfer and flow evolution in transient rectangular free jet of air. International Communications in Heat and Mass Transfer, 108, 104290.

21. Di Venuta, I., Petracci, I., Angelino, M., Boghi, A., \& Gori, F. (2018). Numerical simulation of mass transfer and fluid flow evolution of a rectangular free jet of air. International Journal of Heat and Mass Transfer, 117, 235-251. 
22. Zhou, Y., Fan, D., Zhang, B., Li, R., \& Noack, B. R. (2020). Artificial intelligence control of a turbulent jet. Journal of Fluid Mechanics, 897.

23. Murphy, H. R., \& Miller, D. R. (1984). Effects of nozzle geometry on kinetics in free-jet expansions. The Journal of Physical Chemistry, 88(20), 4474-4478.

24. Ashforth-Frost, S., \& Jambunathan, K. (1996). Effect of nozzle geometry and semi-confinement on the potential core of a turbulent axisymmetric free jet. International Communications in Heat and Mass Transfer, 23(2), 155-162.

25. Attalla, M., \& Salem, M. (2013). Effect of nozzle geometry on heat transfer characteristics from a single circular air jet. Applied thermal engineering, 51(1-2), 723-733.

26. Rahman, M. S., Tay, G. F. K., \& Tachie, M. F. (2019). Effects of nozzle geometry on turbulent characteristics and structure of surface attaching jets. Flow, Turbulence and Combustion, 103(3), 797-825.

27. Hatanaka, K., \& Saito, T. (2012). Influence of nozzle geometry on underexpanded axisymmetric free jet characteristics. Shock Waves, 22(5), 427-434.

28. Hussein, H. J., Capp, S. P., \& George, W. K. (1994). Velocity measurements in a high-Reynolds-number, momentum-conserving, axisymmetric, turbulent jet. Journal of Fluid Mechanics, 258, 31-75.

29. Laban, A., Aleyasin, S. S., Tachie, M. F., \& Koupriyanov, M. (2019). Experimental investigation of nozzle spacing effects on characteristics of round twin free jets. Journal of Fluids Engineering, 141(7).

30. Mi, J. B., Kalt, P., Nathan, G. J., \& Wong, C. Y. (2007). PIV measurements of a turbulent jet issuing from round sharp-edged plate. Experiments in fluids, 42(4), 625-637.

31. Faghani, E., Maddahian, R., Faghani, P., \& Farhanieh, B. (2010). Numerical investigation of turbulent free jet flows issuing from rectangular nozzles: the influence of small aspect ratio. Archive of applied mechanics, 80(7), 727-745.

32. Akbarzadeh, M., Birouk, M., \& Sarh, B. (2012). Numerical simulation of a turbulent free jet issuing from a rectangular nozzle. Computational Thermal Sciences: An International Journal, 4(1).

33. Aravindh Kumar, S. M., \& Rathakrishnan, E. (2017). Nozzle aspect ratio effect on supersonic elliptic jet mixing. Journal of Fluids Engineering, 139(10).

34. Morris, E. M., Aleyasin, S. S., Biswas, N., \& Tachie, M. F. (2019, July). Experimental Investigation of Nozzle Orientation Effects on Mixing Characteristics of Elliptic Triple Free Jets. In Fluids Engineering Division Summer Meeting (Vol. 59025, p. V001T01A078). American Society of Mechanical Engineers.

35. Belovich, V. M., \& Samimy, M. (1997). Mixing processes in a coaxial geometry with a central lobed mixer-nozzle. AIAA journal, 35(5), 838-841.

36. Hu, H., Saga, T., Kobayashi, T., \& Taniguchi, N. (2002). Mixing process in a lobed jet flow. AlAA journal, 4O(7), 1339-1345.

37. Sawyer, R. A. (1963). Two-dimensional reattaching jet flows including the effects of curvature on entrainment. Journal of Fluid Mechanics, 17(4), 481-498. 
38. Newman, B. G. (1961). The deflection of plane jets by adjacent boundaries-Coanda effect. Boundary layer and flow control.

39. Levin, S. G., \& Manion, F. M. (1962). Fluid Amplification. 5. Jet attachment distance as a function of adjacent wall offset and angle. Harry Diamond Labs Adelphi MD.

40. Lai, J. C. S., \& Lu, D. (1996). Effect of wall inclination on the mean flow and turbulence characteristics in a two-dimensional wall jet. International journal of heat and fluid flow, 17(4), 377385.

41. Nasr, A., \& Lai, J. C. (2000). The effects of wall inclination on an inclined offset jet. In 10th International Symposium Applications of Laser Techniques to Fluid Mechanics, Lisbon.

42. Malicki, M. (1966). Wentylacja i klimatyzacja. Wydawnictwa Politechniki Warszawskiej.

43. Iguchi, M., \& Ilegbusi, O. J. (2011). Modeling multiphase materials processes (pp. 95-174). New York: Springer.

44. Feng, J., \& Joseph, D. D. (1996). The motion of a solid sphere suspended by a Newtonian or viscoelastic jet. Journal of Fluid Mechanics, 315, 367-385.

45. Gromow, E., \& Wierciński, Z. (2002). Polepszenie rozdziału powietrza w pomieszczeniu wentylowanym za pomocą niestacjonarnego ef ektu Coanda. Ciepłownictwo, Ogrzewnictwo, Wentylacja, 33(10), 27-29.

46. Sawyer, R. A. (1963). Two-dimensional reattaching jet flows including the effects of curvature on entrainment. Journal of Fluid Mechanics, 17(4), 481-498.

47. Allery, C., Guérin, S., Hamdouni, A., \& Sakout, A. (2004). Experimental and numerical POD study of the Coanda effect used to reduce self-sustained tones. Mechanics Research Communications, 31(1), 105-120.

48. Skotnicka-Siepsiak, A. (2018). Hysteresis of the Coanda Effect. Journal of Fluids Engineering, 140(1).

49. Skotnicka-Siepsiak, A. (2021). The Applicability of Coanda Effect Hysteresis for Designing Unsteady Ventilation Systems. Energies, 14(1), 34.

\section{Figures}




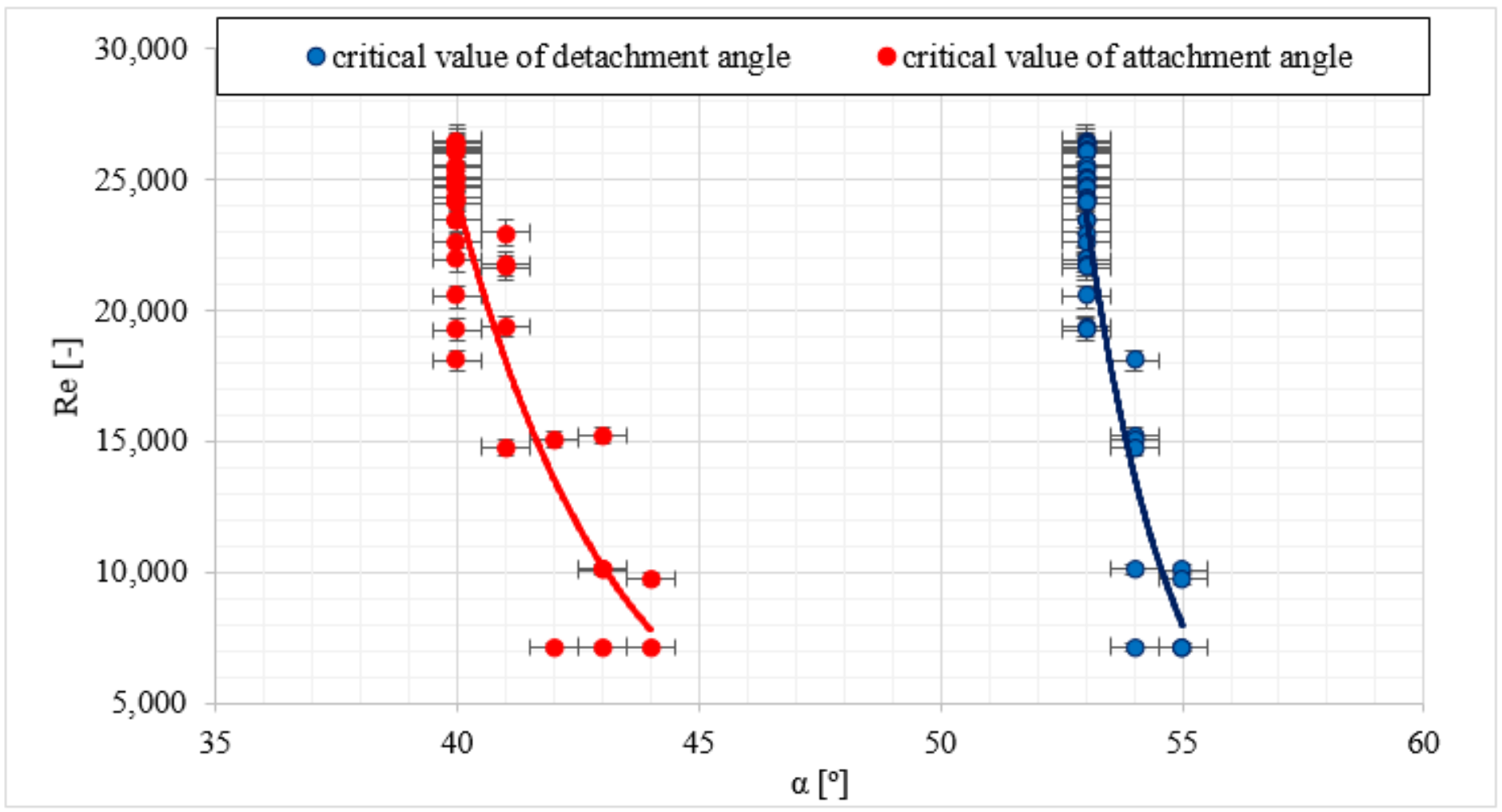

Figure 1

The range of occurrences for the hysteresis of the Coanda effect - critical values of the aD detachment angle and the aA reattachment angle.

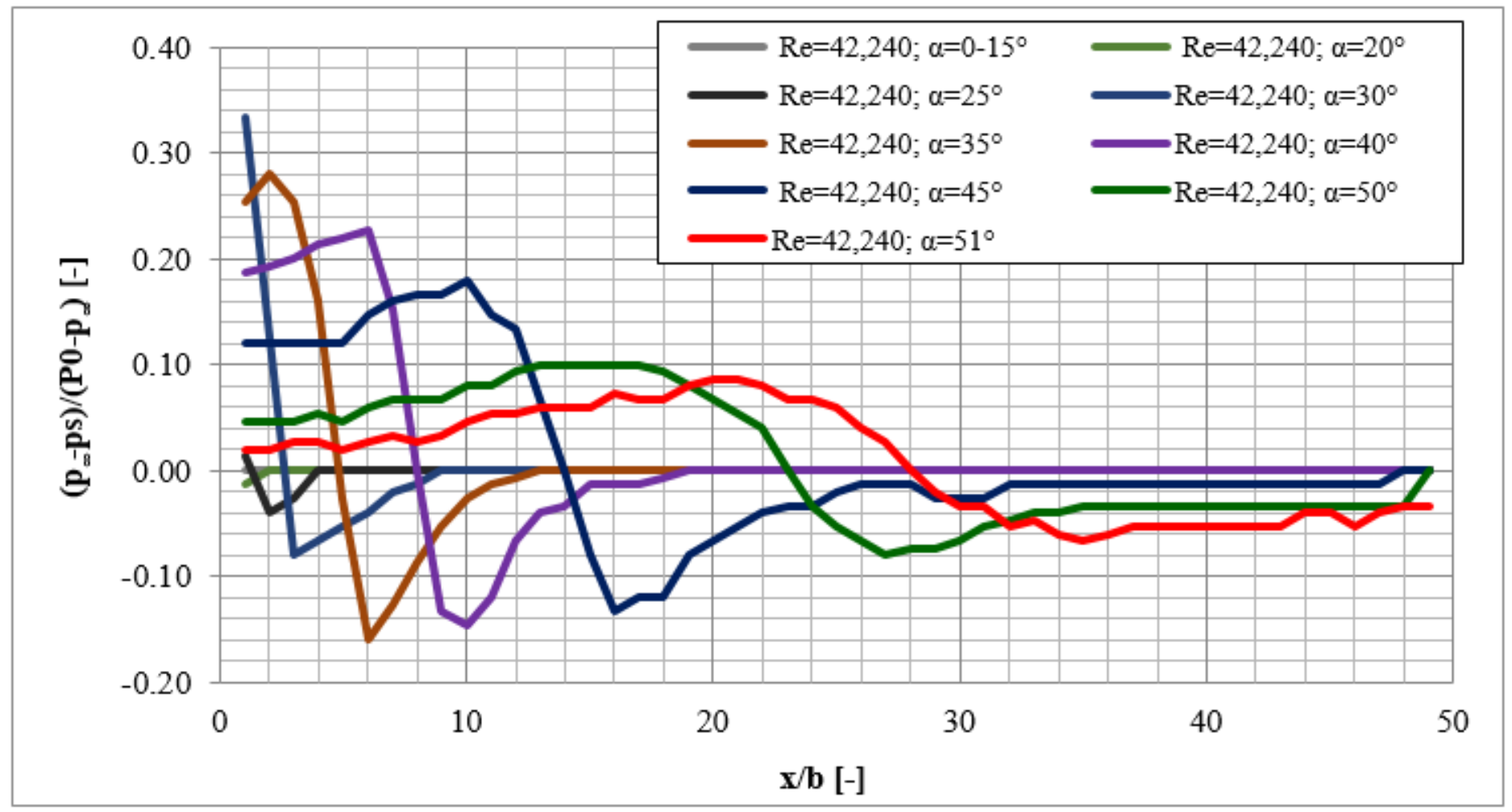

Figure 2 
The pressure distributions on the plate - examined in the direction of detachment $\operatorname{Re}=42,240$; (where static pressure (ps); the pressure of maximal airstream (P0); static pressure of the surrounding fluid at rest $(p \infty))$.

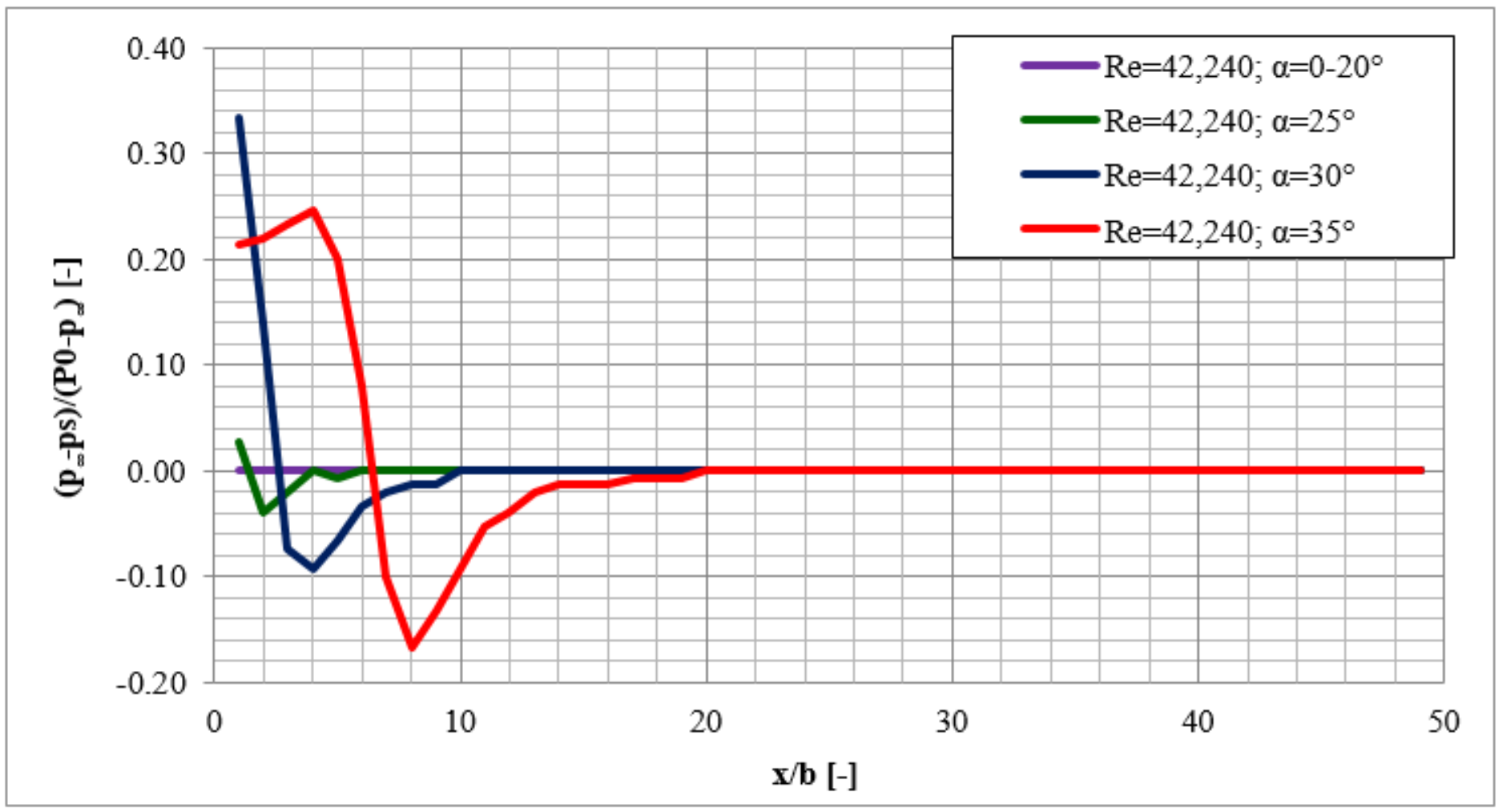

\section{Figure 3}

The pressure distributions on the plate - examined in the direction of attachment $\operatorname{Re}=42,240$; (where static pressure on the surface of the inclined flat plate (ps); stagnation pressure of the fluid supplying the jet (P0); static pressure of the surrounding fluid at rest $(\mathrm{p} \infty))$. 


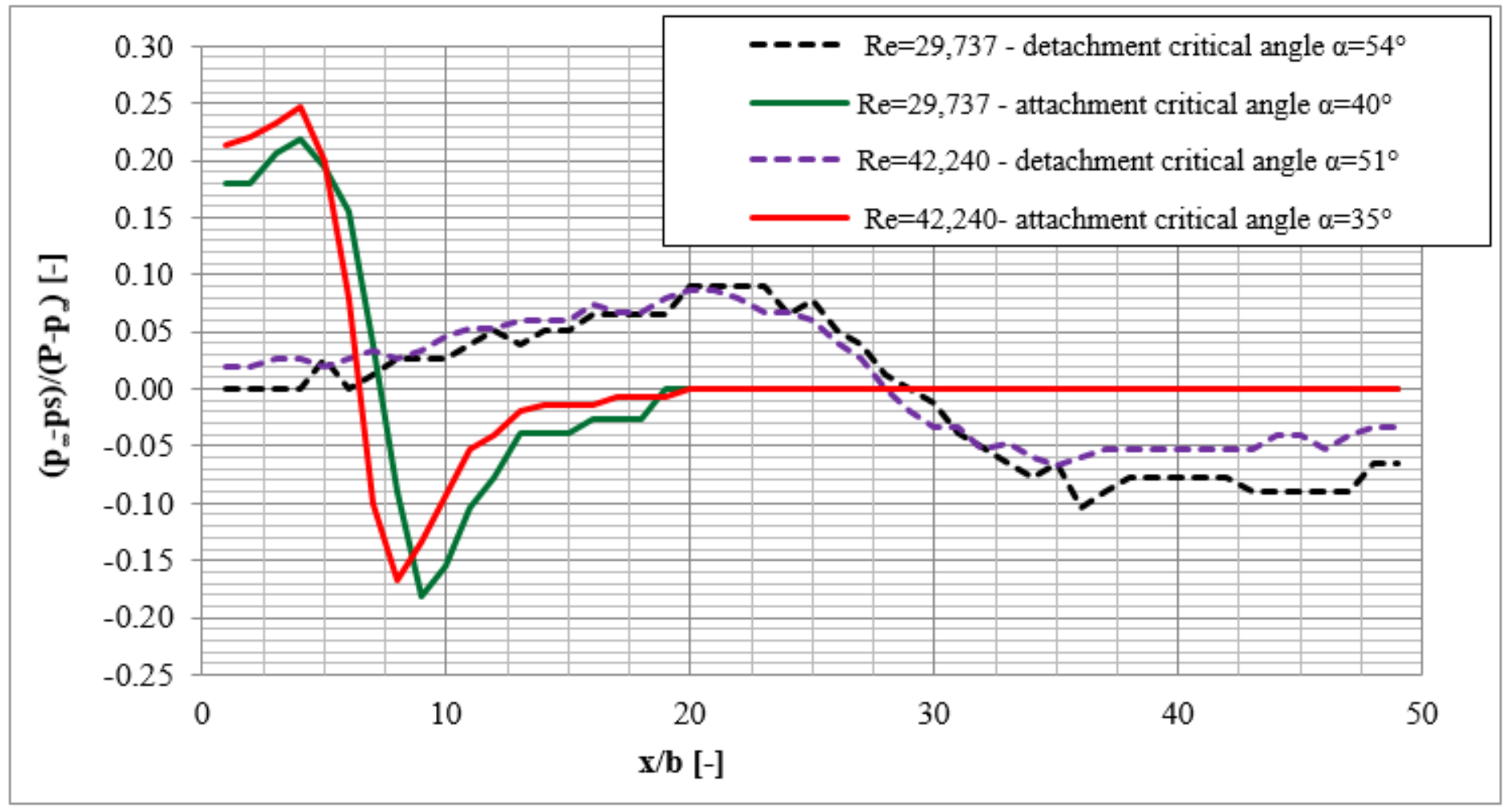

Figure 4

The comparison of the pressure distributions on the plate for critical attachment and detachment angles for selected measuring sessions with $\operatorname{Re}=29,737$ and $\operatorname{Re}=42,240$.

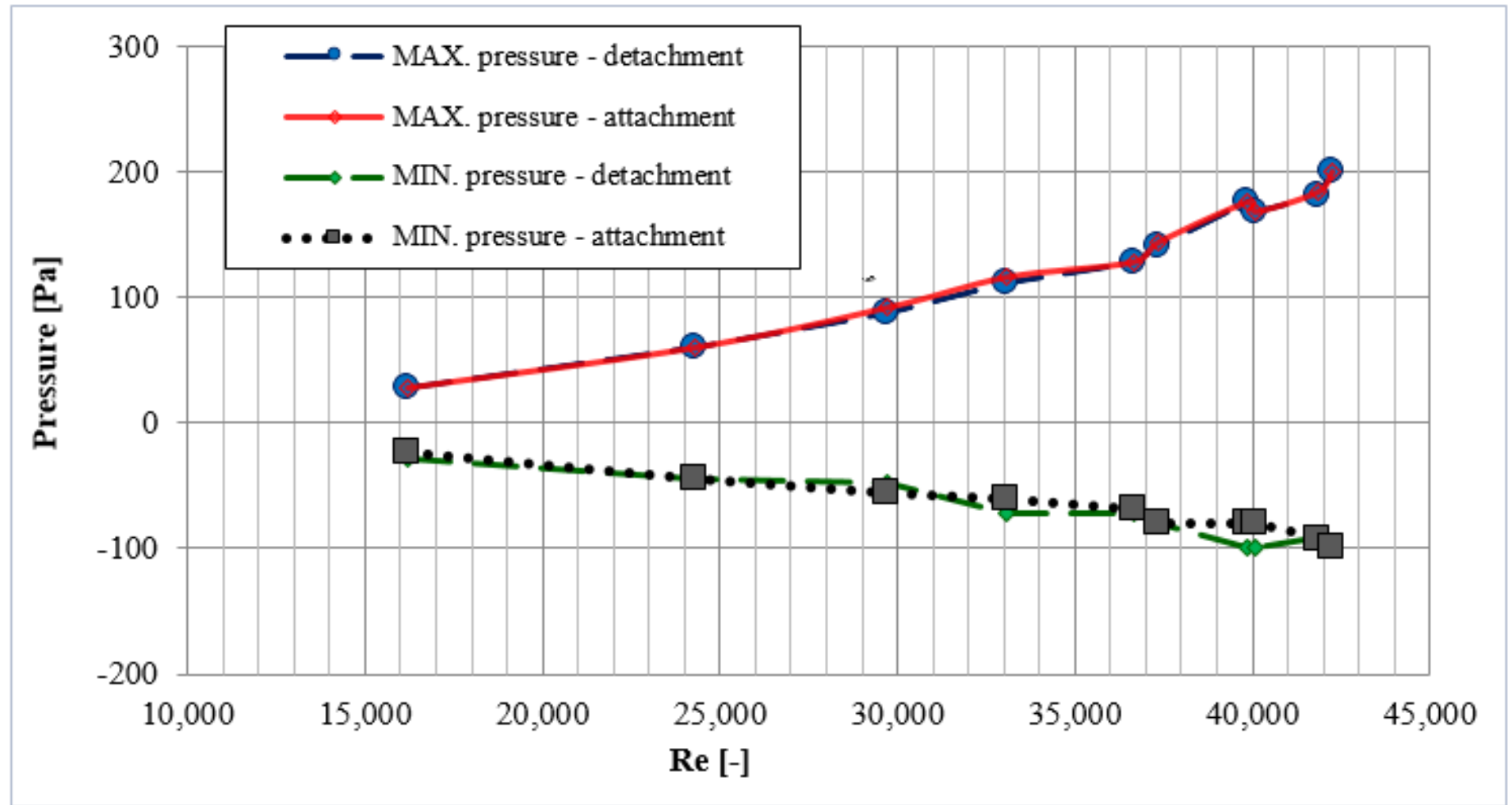

Figure 5 
The minimum and maximum values of pressure pi for the examinations in the direction of detachment and attachment depending on the value of the Reynolds number.

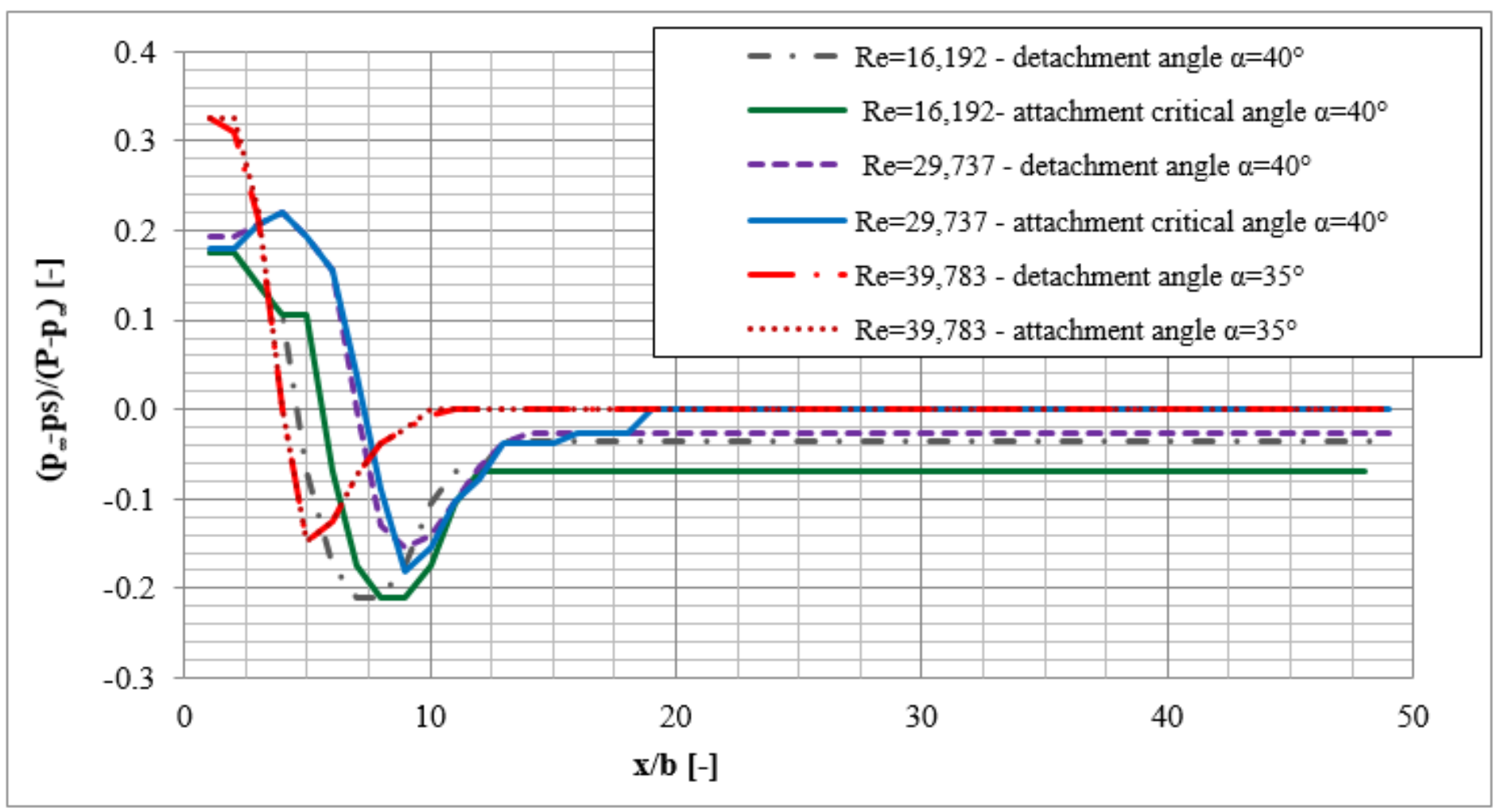

\section{Figure 6}

The comparison of pressure distributions on the plate at the same value of the plate inclination for the examinations in the direction of detachment and attachment. 


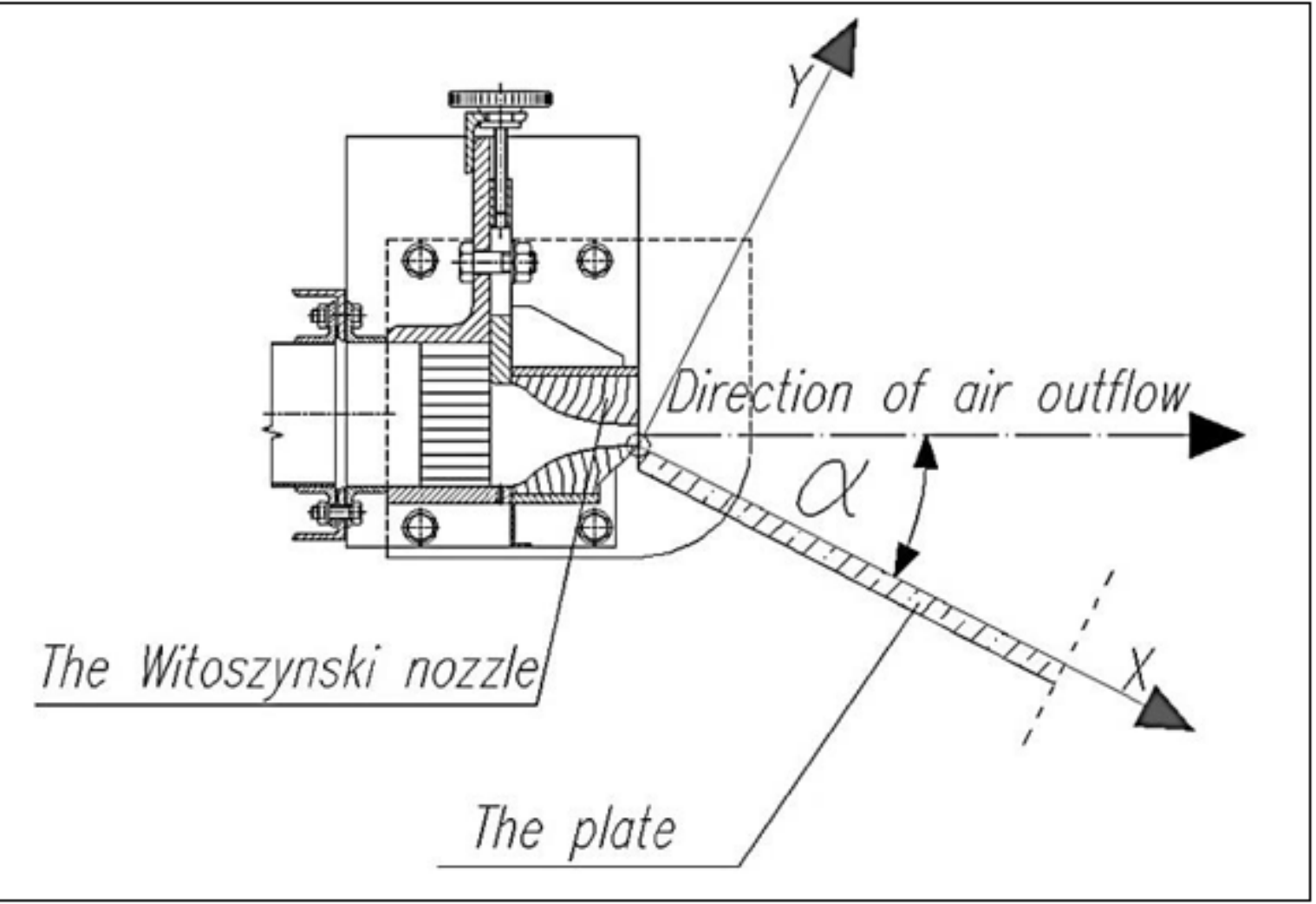

Figure 7

The system of the Witoszyński nozzle and a plate with variable angle of inclination on a measuring station - the view from the top.

\section{Supplementary Files}

This is a list of supplementary files associated with this preprint. Click to download.

- GraphicalAbstracts.jpg 